\section{Right superior vena cava draining into the left atrium with left superior vena cava draining into the right atrium}

Patients with a right to left shunt frequently present with brain abscesses because any organism carried in the venous blood may shunt the physiological lung filter and be carried in the systemic circulation. ${ }^{1}$ In a patient with a brain abscess we found a congenital type of right to left shunt that has not been reported.

\section{Case report}

A 44 year old healthy man presented with a large parietal brain abscess. He had a two week history of fever, headache, and nausea, and a left lateral homonymous hemianopia with bilateral papilloedema was found. A puncture yielded $15 \mathrm{~cm}^{3}$ of pus from the abscess, and three months of treatment with ceftriaxone ( $3 \mathrm{~g}$ daily by a single intravenous bolus) was started. Neurological examination and computed tomography yielded normal results within 15 days and three months, respectively. No causative organism was isolated.

Clinical examination of the chest, echocardiography, chest radiography, and tests of immunological and renal functions yielded normal results. Although this patient's physical activities had been normal, he had mild digital clubbing and mild hypoxia $(85 \mathrm{~mm} \mathrm{Hg}$ ) but no cyanosis. Before treatment with antibiotics was stopped he underwent pulmonary angiography. A catheter, introduced through the cubital vein of the right arm, was pushed into a small right superior vena cava draining into the left atrium and receiving blood from the right subclavian and jugular veins. Another catheter was introduced through the right femoral vein and pushed gradually into the inferior vena cava, the right atrium, and finally a left superior vena cava draining into the right atrium and receiving blood from left subclavian and jugular veins. There was no anomalous pulmonary blood return or an intracardiac shunt. When a small balloon was inflated into the lower part of the right superior vena cava, just above the left atrium, blood pressure did not

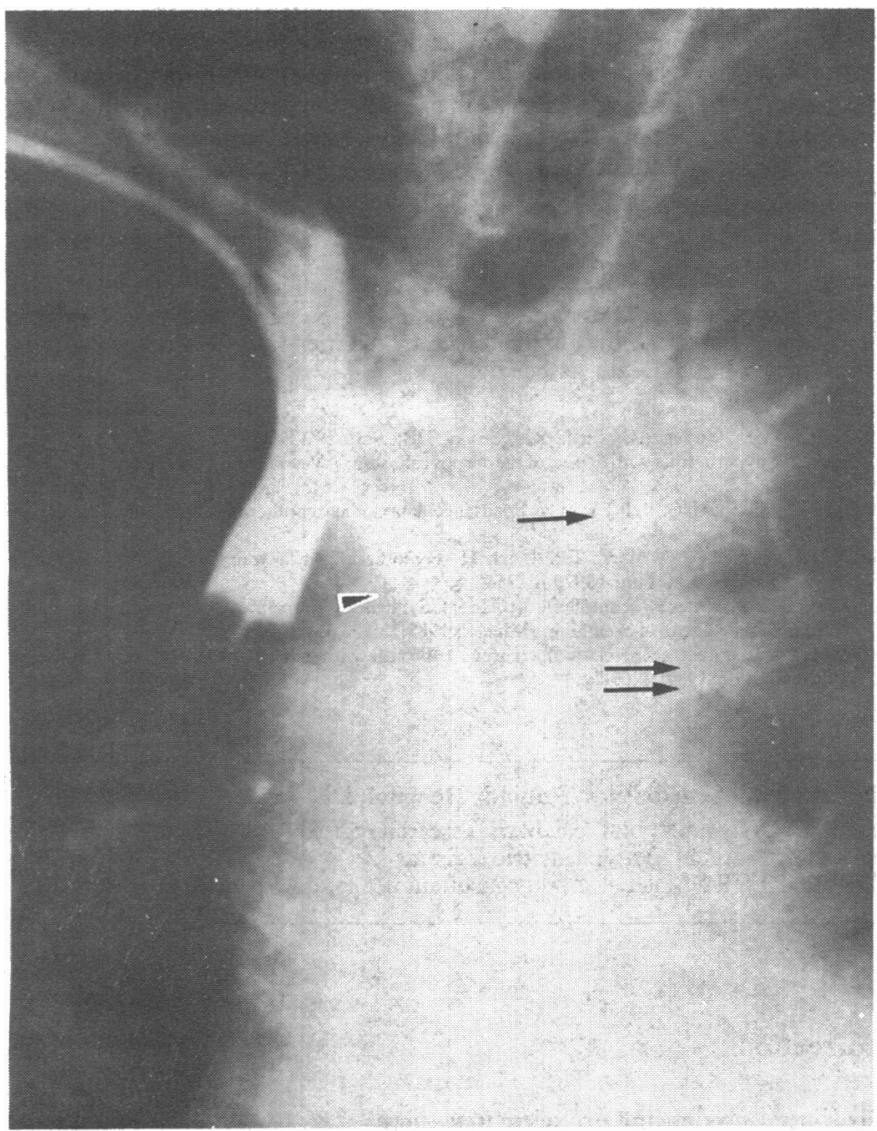

Posteroanterior frame from cineangiocardiography performed in the right superior vena cava. When the blood flow was stopped in the right superior vena cava by a balloon blood went through the anastomosis (single arrow) to the left superior vena cava (double arrow) and the azygos vena (arrow head). increase above and blood passed through an anastomosis to the left superior vena cava and the azygos vena, both draining into the right cavities (figure). The right superior vena cava was ligatured successfully just above the left atrium. No relapse had been reported six months later.

\section{Comment}

We have found no report of a similar anomaly; however, other malformations in the superior vena cava have been reported, usually as a persistent left superior vena cava. A left superior vena cava draining into the left atrium and causing a right to left shunt with cyanosis usually coexists with other cardiac anomalies ${ }^{\prime}$; a persistent left superior vena cava draining into the right atrium is a frequent type of malformation, usually associated with a normal right superior vena cava, and does not cause any haemodynamic change. ${ }^{2}$

A right superior vena cava draining into the left atrium is even rarer. The three reported cases most similar to ours were nevertheless quite different from ours because of clinical evidence of cyanosis during childhood and the absence of brain abscesses in two. ${ }^{3-5}$ In the third case the diagnosis had been made after recurrent brain abscesses, but cyanosis was also evident. In all three cases the right superior vena cava was an isolated anomaly without a persistent left superior vena cava. Our patient's good tolerance and the absence of cyanosis probably resulted from the persistence of a left superior vena cava, normally draining into the right cavities, and the anastomosis, which decreased the shunt flow.

1 Dupuis C, Pernot C, Rey C, Worms AM, Marcon F, Vancostenoble JF. La veine cave supérieure gauche communicant avec l'oreillette gauche. A propos de huit observations. Arch Mal Coeur gauche communican $1981 ; 11: 507-16$.

2 Cha EM, Khoury GH. Persistent left superior vena cava. Radiological and clinical significance. Radiology 1972;103:375-81.

$3 \mathrm{Kirsch}$ WM, Carlsson E, Hartmann AF Jr. A case of anomalous drainage of the superior vena cava into the left atrium. $\mathcal{I}$ Thorac Cardiovasc Surg 1961;41:550-6.

4 Vasquez-Perez J, Frontera-Izquierdo P. Anomalous drainage of the right superior vena cava into the left atrium as an isolated anomaly. Rare case report. Am Heart $\mathcal{f}$ 1979;97:89-91

5 Mornex JF, Brune J, Termet H, Bruyere B, Zhang HF. Une cause exceptionnelle d'hypoxie: l'abouchement de la veine cave supérieure droite dans l'oreillette gauche. Correction chirurgicale. Rev Fr Mal Respir 1983;11:149-55.

(Accepted 7 fuly 1986)

Hôpital B, University of Lille, 59037 Lille Cédex, France

D LEYS, MD, assistant in neurology

$\mathrm{J}$ MANOUVRIER, MD, assistant in cardiology

T DUPARD, $M D$, resident physician in neurosurgery

P KASSIOTIS, MD, assistant in neurology

C REY, MD, assistant in paediatric cardiology

P MARACHE, MD, associate professor in radiology

G DUCLOUX, MD, professor in cardiology

H PETIT, MD, professor in neurology

Correspondence to: Dr Leys.

\section{Munchausen's syndrome by proxy: a warning for health professionals}

False illness, or Munchausen's syndrome by proxy, has become increasingly recognised as a bizarre form of child abuse. ${ }^{1-3}$

An open warning of further injuries to come if no measures are taken to protect the child may be a presentation of child abuse, with bruises and injuries to the mouth being presented without any explanation. ${ }^{4}$ If child abuse is not considered then the child may suffer more serious injuries.

We describe a child presenting with such symptoms, which ultimately proved to be factitious.

\section{Case report}

A girl aged 4 months was brought in by her mother, who complained of bleeding from the child's mouth and blood in the stools. She was the mother's first child and had been conceived when the mother was 15 .

On admission the baby looked well with no cutaneous stigmata or evidence of bruising in the skin. Careful examination of the mouth showed no evidence of injury or haemangioma and subsequent examination under anaesthesia confirmed this. All laboratory investigations yielded normal results.

During the admission the child was shown to medical and nursing staff by the mother with blood apparently coming from the mouth. The mother lived on the 
ward and was not keen to go home. When it was noticed that the mother had a small scratch on the left thumb the possibility of false illness was considered. The amount of blood initially available for analysis was not sufficient to clarify the source of the blood, and after discussions with the local social services department the child was discharged and followed up in the outpatients clinic.

Some eight weeks after the first presentation the child was readmitted with an apparent major haemorrhage from the mouth as evidenced by an area of blood 4 $\mathrm{cm}$ in diameter on the baby's cot blanket. There was no evidence of any bleeding from the child's mouth on examination. The baby was therefore readmitted (with the mother) pending further investigations, and we confirmed that the blood on the cot blanket was of the same group as the mother's.

Subsequently, the parents were confronted with the forensic evidence. The mother initially denied the possibility, but eventually admitted that she had simulated all the bleeding from the child's mouth. Two case conferences were held, and after the second the child was allowed to go home. The child's name was placed on the local child abuse register, arrangements were made for the child to be followed up, and the family was referred to the local child and adolescent psychiatrist, an adult psychiatrist having found no evidence of psychiatric illness in the mother.

\section{Comment}

Ounsted, in his original description of "open warning," commented that people in authority were often unaware of the signs of child abuse. Further experience has indicated the importance of injuries to the head, mouth, and pharyngeal structures as indicators of child abuse. ${ }^{5}$ In this particular case numerous clinical examinations and an examination under anaesthesia failed to establish a site of bleeding. False illness became a definite possibility and was subsequently proved. Certain features favoured this, including the age of the mother, her relationships with her own mother, and the caring behaviour and attention she gave to her child when in hospital.

Thus an open warning, even if it is not an indication of non-accidental trauma, may still point to another area of child abuse. As the presentation initially may be to clinic staff or a general practitioner it is clearly important that such an important symptom as bleeding from the mouth in young babies is not dismissed or ignored.

1 Rogers D, Tripp J, Bentovim A, et al. Non-accidental poisoning: an extended syndrome of child abuse. BrMed f 1976;i:793-6.

2 Meadow R. Munchausen syndrome by proxy. Arch Dis Child 1982;57:92-8.

3 Meadow R. Management of Munchausen syndrome by proxy. Arch Dis Child 1985;60:385-93.

4 Ounsted C. Gaze aversion and child abuse. World Medicine 1975;10:27.

5 Schmitt BD. The child with non-accidental trauma. In: Kempe CH, Helfer RE, eds. The battered child. 3rd ed. Chicago: University of Chicago Press, 1980

(Accepted 26 fune 1986)

Whiston Hospital, Prescot, Merseyside L35 5DR

LAWEH AMEGAVIE, MB, DCH, senior house officer in paediatrics

OMNIA MARZOUK, $\mathrm{MB}, \mathrm{CHB}$, registrar in paediatrics

JOHN MULLEN, BA, CQSW, principal social worker

JOHN SILLS, MB, MRCP, consultant paediatrician

JEAN B M GAUTHIER LE TENDRE, MB, DPM, consultant child and adolescent psychiatrist

Correspondence to: Dr Sills.

\section{Blowing hot and cold: "near miss" sudden infant death and episodic hypothermia}

We report a previously unrecorded association between "near miss" sudden iniant death syndrome and the subsequent development of episodic hypothermia.

\section{Case report}

A previously normal boy was admitted at the age of 9 weeks after being found apnoeic and apparently dead during sleep and resuscitated by vigorous shaking. There was no family history of sudden infant death syndrome or hypothermia. Clinical examination and investigations (including chest radiography, lumbar puncture, and electroencephalography) yielded normal results. Cardiorespiratory monitoring showed frequent episodes of sleep related apnoea and associated bradycardia. He was diagnosed as having had a "near miss" sudden infant death and discharged home with an apnoea mattress. Multiple further episodes (requiring mouth to mouth resuscitation) were treated with oral theophylline and, later, caffeine with limited success. Throughout these episodes his parents did not notice that he felt cold. During an admission when aged 1 he had two episodes of severe apnoea during sleep associated with rectal temperatures of $<35^{\circ} \mathrm{C}$. His daytime temperatures were normal.

At 17 months the near miss episodes stopped but he continued regularly to become hypothermic during sleep, particularly in cold weather. Home rectal temperature recordings (Model 272-Vickers Medical) confirmed that his temperature fell to $32^{\circ} \mathrm{C}$ over 10 minutes in quiet sleep. He felt "deathly cold" without shivering or sweating. Vigorous reheating restored his temperature to normal in about one hour. Various measures failed to prevent these episodes. His development was completely normal.

Investigations, including full blood count, creatine phosphokinase, autoantibody screen, metabolic screen, and measurements of free fatty acids, 24 hour vanillylmandelic acid, and serum thyroxine and thyroid stimulating hormone, gave normal results. An insulin stress test showed normal growth hormone and cortisol responses. Responses to thyroid releasing hormone were normal, as were gonadotrophin responses. Serum prolactin concentration (non-stressed) was normal and cortisol values showed a normal diurnal variation. An early morning urine sample showed normal concentrating ability. No infection was found, and the electrocardiogram, electroencephalogram, and brain stem auditory evoked responses were normal. Maximum end tidal carbon dioxide tension in quiet sleep was $5 \cdot 1 \mathrm{kPa}(38 \mathrm{~mm} \mathrm{Hg})$. A computed tomograph of the head was normal, with the corpus callosum present.

Although the parents did not wish formal tests of temperature control, during an upper respiratory tract infection he became feverish $\left(38^{\circ} \mathrm{C}\right.$ rectal $)$ and sweated.

\section{Comment}

Episodic hypothermia is rare. Although first postulated as "diencephalic epilepsy," Summers et al recognised it as a distinct condition with characteristic sweating attacks often leading to stupor or coma and absence of the corpus callosum in seven of the nine cases that were adequately investigated.'

Our patient had episodic hypothermia without sweating, a normal corpus callosum, and no evidence of hypothalamic dysfunction. He also had recurrent severe apnoea requiring vigorous resuscitation for which no cause could be found. This is the first reported association.

In the absence of temperature studies and control data the cause of his thermoregulatory defect is unknown, but the absence of sweating during an attack makes increased heat loss ${ }^{23}$ unlikely. The most likely explanation for his apnoea and hypothermia is a hypothalamic defect. The hypothalmus is important in temperature control ${ }^{3}$ and may play a part in respiratory regulation. ${ }^{4}$ Hypothermia and apnọea have been associated with agenesis of the corpus callosum. ${ }^{5}$ Hypothalamic endocrine dysfunction has been noted in the absence of structural abnormality. ${ }^{2}$ Structural abnormality has also been seen at necropsy despite normal endocrine values during life. ${ }^{3}$ Our negative results do not therefore completely exclude a hypothalamic lesion.

Although more sudden infant deaths occur in winter, hyperthermia is more favoured than hypothermia as a possible cause. Our patient maintains the interest in the relation between temperature and sudden infant death.

We thank Dr C Brook, Middlesex Hospital, for his helpful comments, the patient's parents, and Miss Audrey Dixon. Dr Kevin Dunne is a Professor MacClancy research fellow jointly funded by the friends of the Rotunda and the Irish Sudden Infant Death Association.

1 Summers GD, Young AC, Little RA, Stoner HB, Forbes WSTC, Jones RAC. Spontaneous periodic hypothermia with lipoma of the corpus callosum. F Neurol Neurosurg Psychiatry 1981;44: 1094-9.

2 Fox RH, Wilkins DC, Bell JA, et al. Spontaneous periodic hypothermia: diencephalic epilepsy. BrMed f 1973;ii:693-5.

3 Fox RH, Davies TW, Marsh FP, Urich H. Hypothermia in a young man with an anterior hypothalamic lesion. Lancet 1970;ii: 185-8.

4 du Rivage SK, Winter RJ, Brouillette RJ, Hunt CE, Noak Z. Idiopathic hypothalamic dysfunction and impaired control of breathing. Pediatrics 1985;75:896-8.

5 Pineda $M$. Familial agenesis of the corpus callosum with hypothermia and apnoeic spells Neuropediatrics 1984;15:63-7.

(Accepted 22 fuly 1986)

Department of Paediatrics, Rotunda Hospital, Dublin 1

K P DUNNE, MRCP, DCH, paediatric research registrar

$M$ MCKAY, MRCPI, DCH, paediatric registrar

T G MATTHEWS, FRCPI, FAAP, consultant neonatologist

\section{Correction}

\section{Cigarette smoking and prolactin in women}

We regret that an error occurred in this article by Dr John A Baron and others (23 August, $\mathrm{p} 482$ ). In the table prolactin values were given in SI units (nmol/l); the conversion at the foot of the table should have read: $1 \mathrm{nmol} / \mathrm{l} \approx 25 \mu \mathrm{g} / \mathrm{l}$, and not as stated, $0.04 \mu \mathrm{g} / \mathrm{l}$ 